\title{
Terms of Office
}

Selected Political Executives in the New York Region, 1954-1981

\section{Governors}

NEW YORK

Thomas E. Dewey January 1943-January 1955

W. Averell Harriman January 1955-January 1959

Nelson A. Rockefeller January 1959-December 1973

Malcolm O. Wilson December 1973-January 1975

Hugh J. Carey January 1975-

NEW JERSEY

Robert B. Meyner

Richard J. Hughes

William T. Cahill

Brendan T. Byrne

CONNECTICUT

John Davis Lodge

Abraham A. Ribicoff

John N. Dempsey

Thomas J. Meskill

Ella T. Grasso

William A. O'Neill

January 1954-January 1962

January 1962-January 1970

January 1970-January 1974

January 1974-

January 1951-January 1955

January 1955-January 1961

January 1961-January 1971

January 1971-January 1975

January 1975-December 1980

January 1981--

\section{Mayors of Newark}

Leo P. Carlin

Hugh J. Addonizio

Kenneth A. Gibson

\section{Mayors of New York City}

Robert F. Wagner

John V. Lindsay

Abraham D. Beame

Edward I. Koch

May 1953-July 1962

July 1962-July 1970

July 1970 .

January 1954-January 1966 January 1966-January 1974 January 1974-January 1978 January 1978 